\title{
The Development of Filtration and Bioremediation Technique for Decontaminating Bitumen-Polluted Water
}

\author{
Eganoosi Esme Atojunere ${ }^{1}$, Kolawole Ogedengbe ${ }^{2}$ and Emmanuel Babajide Lucas ${ }^{2}$ \\ ${ }^{1}$ University of Lagos, Yaba, Akoka \\ Lagos, Nigeria \\ eatojunere@unilag.edu.ng \\ ${ }^{2}$ University of Ibadan \\ Ibadan, Nigeria \\ k.ogedengbe@ui.edu.ng; eb.lucas@ mail.ui.edu.ng
}

\begin{abstract}
Water resources in some areas of Ondo State, Nigeria, are polluted by suspended oily solids, toxic metals and dissolved petroleum hydrocarbons. Non-exploitation of the bitumen deposits in the areas for commercial purpose has aggravated this level of pollution. The objective of the work was to develop a decontamination facility for small-to- medium scale operation. A Bitumen Polluted Water Treatment System (BPWTS) was designed and fabricated using acrylic glass (Perspex) material and with appropriate flow kinetics. The BPWTS comprised four columns for filtration and bioremediation. Processed Chicken feather (PCF) and African walnut seed shells were biosorbents at stages 1 and 3, while stage 2 was for bioremediation with Pseudomonas aeruginosa as inoculum and stage 4 was for water discolouration using activated charcoal. Bitumen-polluted water samples from affected streams and wells were run through the BPWTS and the removal efficiency (RE) was determined. Treated water at each stage was tested for turbidity, $\mathrm{pH}$, suspended solids,toxic metals and dissolved petroleum hydrocarbon. Suspended solids reduced from $1.2 \times 10^{3}$ to $6.2 \times 10 \mathrm{mg} / \mathrm{L}$ in stage 1, indicating PCF's good oleophilic properties. This prevented the bitumen solids from reaching other stages. At stage 2, Pseudomonas aeruginosa reduced concentrations of lead $\left(1.0 \times 10^{-2}\right.$ to $\left.1.0 \times 10^{-3} \mathrm{mg} / \mathrm{L}\right)$, benzene $(3.7$ to $2.5 \mu \mathrm{g} / \mathrm{L})$, p-xylene $(3.2$ to $1.2 \mu \mathrm{g} / \mathrm{L})$ and o-xylene $(3.2$ to $1.2 \mu \mathrm{g} / \mathrm{L})$. At stage 3 , residual solids were removed and in stage 4 discolouration of water reduced from 15.60 to $0.98 \mathrm{HU}$. Pollution indices of treated and untreated water samples were significantly different. The RE of the BPWTS were $95.0 \%$ for suspended solids, zinc $82.0 \%$, benzene $70.0 \%, o$-xylene $65.0 \%, p$-xylene $65.0 \%$ and lead $62.0 \%$, bringing the treated water to within permissible level for potable water. Decontamination and bioremediation technique developed reduced water pollution indicators, and in turn health risk to human beings.
\end{abstract}

Keywords: Biosorbents Materials, Pseudomonas Aeruginosa, Decontamination, Removal Efficiency.

\section{Introduction}

Ondo State of Nigeria is rich in water resources. However, large-scale pollution by bitumen has rendered the water resources unsafe, especially for domestic purposes[1]. The fishes, plants, animals, the environment and humans in the area are at great risk. There is need to decontaminate water drawn from the affected water sources using affordable means. Chicken feathers and African walnut(Plukenetia conophora)(Tetracarpidium conophorum) seed shells being oleophillic, were identified as waste products of potential for filtration of oily pollution of water. Such application is doubly beneficial. Chicken feather is hardly biodegradable. It is between 4 to $6 \%$ the mass of chicken, and it has been found to be of little or no large scale application and now constitutes a nuisance to the environment. It is available in large quantities as waste[2,3]. African walnut seeds shells are of low availability and there is no center for mass collection. This situation may however change if some important usage is identified[4]. The potential of using chicken feather to decontaminate polluted water has been reported by[5,6].The methods of pollutant removal could be by physiosorption or chemisorption[6].The former involves trapping pollutants from the influents on their pores'network while the latter is through their chemical functional groups. The removal of heavy metal contaminants from electroplating plant effluent with sorbents made from agricultural wastes (sawdust and teak tree bark) has been demonstrated[7].Such low-cost adsorbents have also been used to remove other metals from electroplating waste. Activated carbon has been used to remove metals from dye-polluted water[7]. It was found in the work that toxic metals uptake by the sorbent started within 10 to 60 minutes and the optimum 
bound was $\mathrm{pH}$ dependent. Bioremediation is a technique that is designed to boost the natural biodegradation of pollutants found in contaminated water and soil through reactions carried out by selected microorganisms[8,9]. Contaminated media are exposed to an army of microorganisms which gobble up the contaminants and said to leave behind harmless substances such as carbon dioxide and water[10].For bioremediation to occur, an electron acceptor and microorganisms that have the potential to remove specific pollutants have to be present[10]. There are a number of microorganisms that have been screened for their hydrocarbon utilizing potential[11,12]. Bacillus and Pseudomonas species are the most studied and are plentiful in water and soil environments. Hydrocarbons are substances that contain hydrogen and carbon, mostly petroleum compounds including bitumen. The use of microorganisms in pollution abatement is gaining interest due to its advantages over the conventional water treatment methods. They are cheaper and more effective. This work was designed to test some of these strains in combination with filtration method on bitumen-polluted water to contain its pollutants.

\section{Materials and Methods}

\subsection{Areas of Ondo State Where There Are Bitumen Deposits}

The bitumen deposits in the State were found to be situated between longitude $4^{\circ} 30^{1}$ and $5^{\circ} \mathrm{E}$. Major communities' streams and wells that are affected include Agbabu, Ilubinrin, Lodasa and Boridele.

\subsection{Water Samples Collection and Analyses}

The water sampling, storage, preservation and transportation to the laboratory were carried out in accordance with established specification[13]. A 20-litre capacity container was used to collect polluted water pooled from streams and wells at Agbabu, Ilubirin, Lodasa and Boridele. These were taken at depths $10-20 \mathrm{~cm}$ below the water surfaces and the concentration of some target water pollution indicators were determined in line with APHA [14]. Samples were run through the developed BPWTS, and at each stage, the removal efficiency was determined.

\subsection{Collection and Processing of Chicken Feather and African Walnut Plukenetia conophora) (Tetracarpidium conophorum) Seeds Shell}

Chicken feathers were collected from ZARTECH Limited in Ibadan, Oyo State of Nigeria which engaged in poultry farming and chicken and meat processing. After collection, grits, stones, tissues and blood stains were removed and the samples were washed with detergent, rinsed thoroughly with clean water, air-dried for five (5) days and ground using hammer mill. They were sieved and stored as shown in Figures 1-3. Similar procedures in Figures 4-6 were followed for African walnut seed shells purchased locally at Ilesa, Osun State, Nigeria.

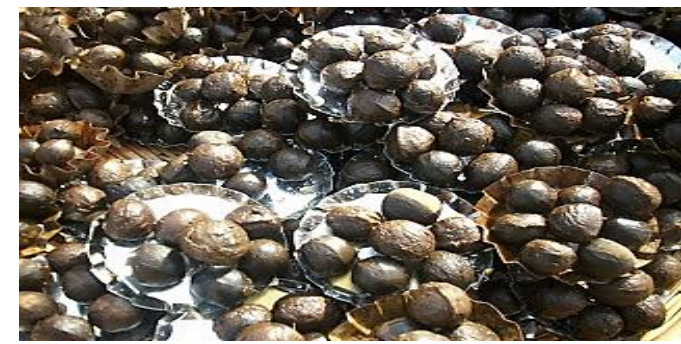

Fig. 1: African Walnut seeds shells before cracking.

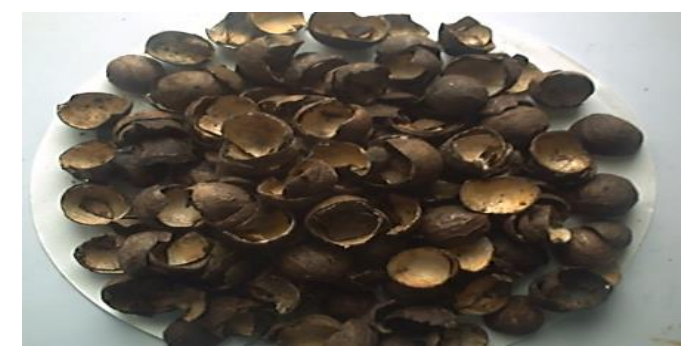

Fig. 2: African walnut seeds shells after cracking. 


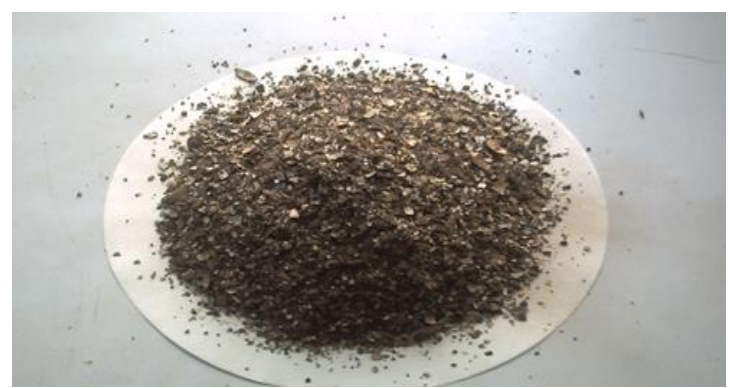

Fig. 3: African walnut seeds shells after milling.

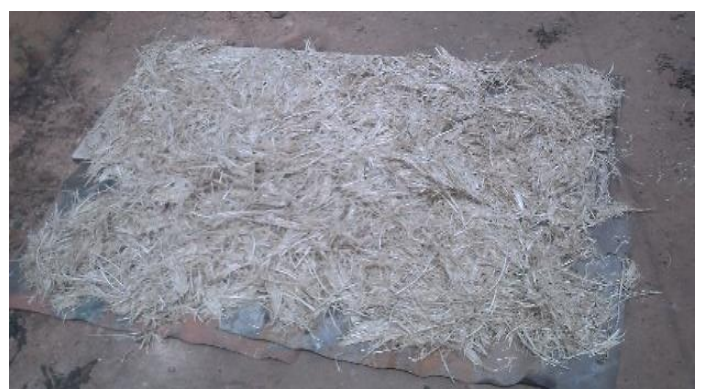

Fig. 4: Chicken feathers before drying.

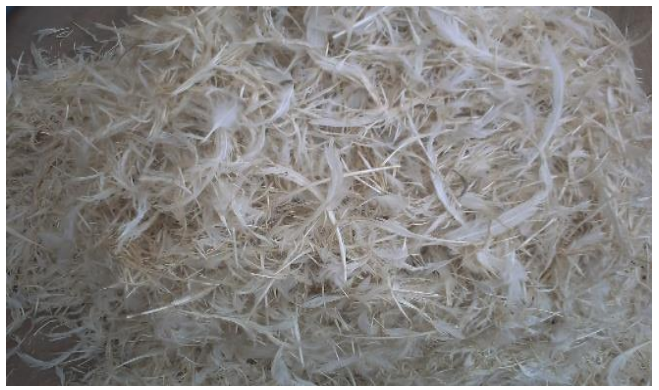

Fig. 5: Chicken feathers after drying.

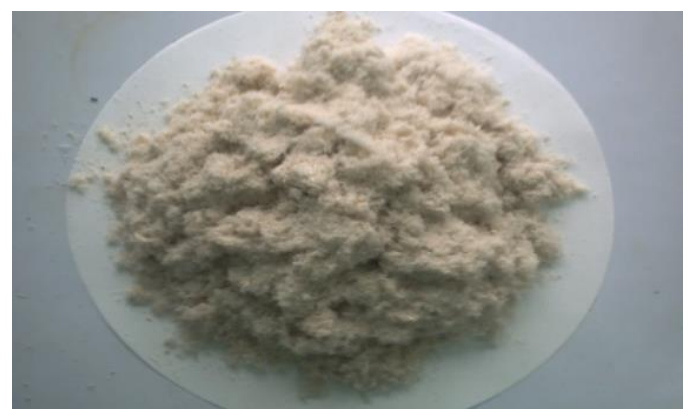

Fig. 6: Chicken feathers after milling.

\subsection{Constructional and Other Materials}

The materials and equipment employed in this work are:

\subsubsection{Materials/Components and Equipment}

i. Sheets of perspex acrylic glass (4.5 $\mathrm{mm}$ thick)

ii. Sheets of clear glass (6mm thick)

iii. Transparent Sheet of Plastic Board (5mm thick)

iv. Connecting pipes (external diameter 20mm) 
v. Gate valves

vi. 4-litre capacity plastic containers

vii. Bitumen -polluted water(BPW)from the four locations

viii. (10) $500 \mathrm{ml}$ glass bottles for water samples collection

ix. The bitumen- polluted water treatment systems

x. pH Meter (HI96107), range:0 to14

xi. Atomic absorption spectrophotometer (AAS) A Analyst 200, PerkinElmer

xii. Gas Chromatography 6890N, Mass Spectrometer 5975C, Agilent Technologies

xiii. Mercury in glass thermometer

xiv. (20) Sets of test tubes

$\mathrm{xv}$. Laboratory scale pressure cooker

xvi. Gallenkamp bacteriological Incubator with Fan Size 2, temperature Range: Ambient to $90^{\circ} \mathrm{C}$, measures $580 \mathrm{~mm}$ W X 460 D X $710 \mathrm{H}$

xvii. Memmert universal oven, temperature up to $300^{\circ} \mathrm{C}$

xviii. Air pump (Resun Ac-9901/Ac)

xix. An electrically operated binocular microscope by Zeiss, West Germany

\subsection{Design, Fabrication and Operation of the BPWTS}

The developed purification system consists of four glass-supported rectangular columns made of synthetic polymer connected together in series by poly vinyl chloride (pvc) pipe. Other jointing accessories were glues used for water tight of the column and pipes assembly. The dimensions of each column were: column 1: $400 \mathrm{~mm}$ x160 mm x160 mm: column 2:200 mm x160 mm x160 mm, column 3: $270 \mathrm{~mm} \times 160 \mathrm{~mm}$ x160 mm and column 4: 200mm x160 mm x160 mm. Columns 1,3 and 4 have cups of uniform dimension of $6 \mathrm{~mm}$ x $6 \mathrm{~mm}$ by $160 \mathrm{~mm}$ and, were filled with sorbents to $4 \mathrm{~mm}$ depths. All columns had squared protective top lids of $160 \mathrm{~mm}$ x $160 \mathrm{~mm}$ x $6 \mathrm{~mm}$ dimensions. Figure 7 shows the schematic diagram of the BPWTS. 


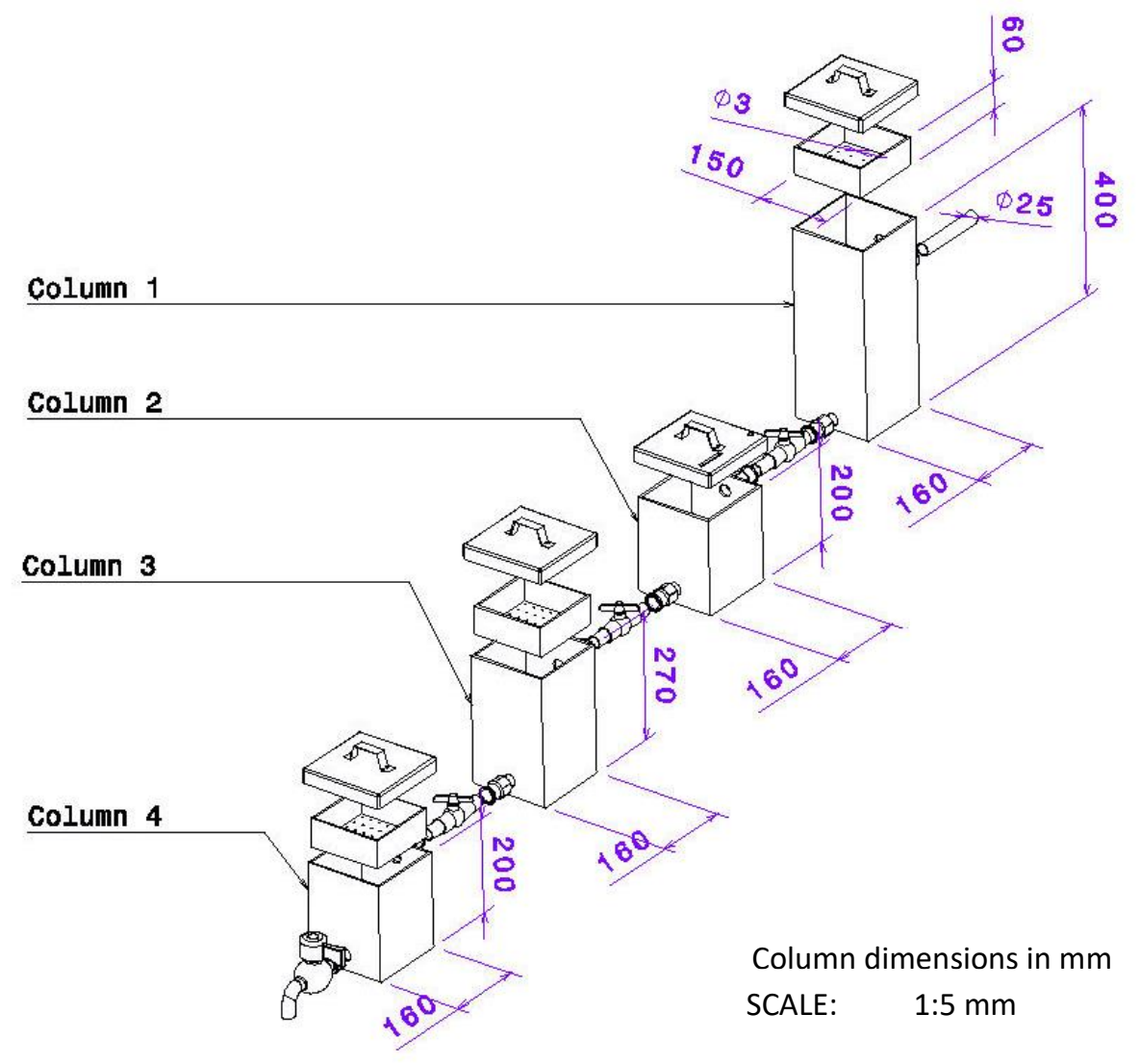

Fig. 7: The schematic diagram of the Bitumen-Polluted Water Treatment System (BPWTS).

\subsubsection{Description of Equipment}

At column 1, the discharge flow rate was set at $0.4 \mathrm{~L} / \mathrm{min}$. to allow movement of influent from the tank to the purification system by gravity. As the influent entered the column, it dropped directly on the single medium filter cup filled with Powdered Chicken Feather (PCF). At time intervals of 5 minutes, the PCF attained saturation which paved way for the influent to flow through the netted $3 \mathrm{~mm}$ holes in the cup. Filter media needs replacement after 3 runs. The adsorbent was frequently replaced to have a good flow through as necessary. Column 2, fresh culture of Pseudomonas aeruginosa was prepared on nutrient agar and incubated for 24 hours in an oven set at $37^{\circ} \mathrm{C}$ for growth by sub-culturing from the pure stock culture. A mixture of $250 \mathrm{ml}$ of nutrient broth was prepared and dispensed with a single streak of resuscitated Pseudomonas aeruginosa, thoroughly mixed and incubated for 24 hours for growth. After growth was observed, the flask was shaken for homogeneity, inoculated into column 2 containing three (3) liters of treated influent from column 1 and physico-chemical changes in the medium were determined. The average $\mathrm{pH}$ value and temperature of the medium were maintained at 7.1-7.9 and $26-27^{\circ} \mathrm{C}$ respectively. Column 2 was airtight, holes and ports were cotton plugged wrapped with aluminum foil and column body covered with a black jacket throughout for 48hours and was aerated with air pump for 24hours.

The air pump was of $25 \mathrm{~mm}$ diameter and $4 \mathrm{~mm}$ length. It had air stone supplying pressure of $0.012 \mathrm{Mpa}$ and a capacity to aerate at 1.8 liters of water per minute. Other monitoring instruments inserted were a mercury in glass thermometer to measure temperature, $\mathrm{pH}$ meter with a scale of 0-14 measuring changes in acidity and alkalinity of the mixture that lasted 48hours. Aeration was supplied to the medium for 24 hours using a Resun Ac-9901/AC air pump pipe having one outlet. The effluent was further treated at stage 3 with Processed African walnut (PAW) seed shells and, at stage 4 with activated charcoal for discoloration. For column 3, the effluent of stage two was transferred to stage three as the control tap three (3) was opened. The effluent flowed over the sorbent as residual suspended solid was retained on its surface. The sorbent of processed African walnut seed shells, milled close to powder was used to remove residual solids that have passed through 
stages 1 and 2. Column 4 was set to remove colouration from the treated water, using granular activated charcoal. In it also Treated Bitumen Polluted Water (TBPW) was chlorinated to destroy bacteria strains that have passed into the final treated water. The whole experiment from stage one to four was repeated and TBPW samples were taken for metal and hydrocarbon analyses. The spent sorbents used in all the filtration zones were oven- dried before disposal. This was to prevent, sorbent laden with pollutants causing secondary pollution. Test results were compared with permissible limits.

\section{Results and Discussions}

\subsection{The Efficiency of BPWTS in Decontaminating of BPW Sourced from Agbabu, llubirin, Lodasa and Boridele}

GC/MS analyses for hydrocarbons on treated bitumen-polluted water samples showed $70 \%$ reduction for hydrocarbon concentration, $65 \%$ for benzene, $65 \%$ for xylene and $65 \%$ for p-xylene, $65 \%$ for o-xylene, $62 \%$ for lead and $65 \%$ for pxylene from initial $(100 \%)$ present before treatment. These removals occurred largely at stage 2 which was bioremediation. This suggests that chicken feather's sorbent in stage 1, had preference for suspended solid bitumen. Stage 1 had no possible removal on dissolved pollutants. The dissolved hydrocarbons would have freely passed through stage 1 . The sorbent at stage 1, trapped about 95\% of suspended bitumen as shown in Figures 8 and 9, and residual was removed by processed African walnut seeds shell at stage. As the filtrates were moved down to other treatment zones, their bitumen loads were lowered.

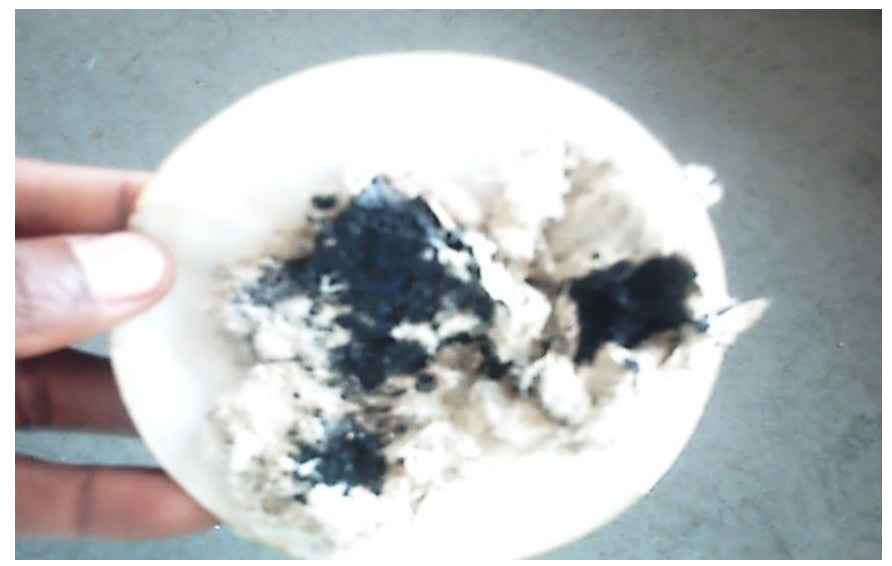

Fig. 8: Bitumen trapped by PCF sorbent during stage 1.

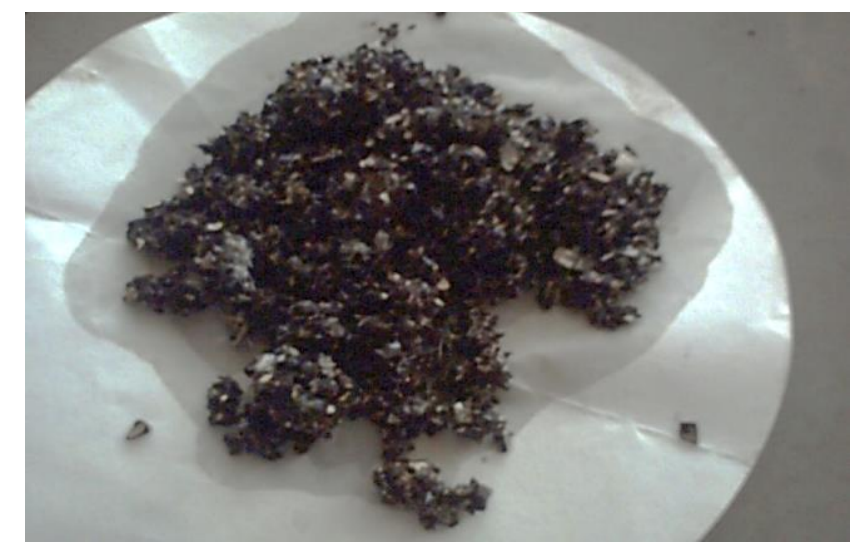

Fig. 9: Bitumen entrapped by PAW seed shells during stage 3.

At stage 2, Pseudomonas aeruginosa strain reduced the concentrations of toxic metals and hydrocarbons present as shown in Table 1. The indicators with highest pollutant removal efficiency were suspended solids $(1250 \mathrm{mg} / \mathrm{L}$ reduced to $62 \mathrm{mg} / \mathrm{L})$ and the least was for cadmium $(0.59 \mathrm{mg} / \mathrm{L}$ reduced to $0.25 \mathrm{mg} / \mathrm{L})$, as illustrated in Figure 10 . The reduction in other pollutant concentrations, $82 \%$ for zinc, $79 \%$, for iron, $62 \%$ for lead, $59 \%$ for chromium and for Nickel $47 \%$ as shown in Table 1. 
Table 1: Treated Bitumen Polluted Water Pollutants Removal Efficiencies.

\begin{tabular}{|c|c|c|c|c|}
\hline $\begin{array}{l}\text { Pollutant } \\
\text { indicators }\end{array}$ & $\begin{array}{l}\text { Pollutant presence in } \\
\text { untreated water } \\
\text { samples }(\mathrm{mg} / \mathrm{L})(\mathrm{A})\end{array}$ & $\begin{array}{l}\text { Pollutant presence in } \\
\text { Water samples after } \\
\text { treatment }(\mathrm{mg} / \mathrm{L})(\mathrm{B})\end{array}$ & $\begin{array}{l}\text { Quantity of pollutant } \\
\text { removed(A-B) mg/L }\end{array}$ & $\begin{array}{l}\text { Removal } \\
\text { Efficiency(RE } \\
\% \frac{A-B}{A} \times \\
100 \%\end{array}$ \\
\hline $\begin{array}{l}\text { Suspended } \\
\text { solids }\end{array}$ & 1244 & 62 & 1182 & 95 \\
\hline Manganese & 0.21 & 0.01 & 0.2 & 95 \\
\hline Zinc & 0.219 & 0.04 & 0.179 & 82 \\
\hline Iron & 14.57 & 6.7 & 7.9 & 79 \\
\hline Benzene & 3.671 & 2.5 & 1.171 & 70 \\
\hline o-xylene & 3.219 & 2.059 & 1.16 & 65 \\
\hline p-xylene & 3.219 & 2.059 & 1.16 & 65 \\
\hline Lead & 0.049 & 0.019 & 0.03 & 62 \\
\hline Chromium & 2.72 & 1.092 & 1.628 & 59 \\
\hline Cadmium & 0.59 & 0.25 & 0.34 & 58 \\
\hline
\end{tabular}

The low removal efficiency of the BPTWS for cadmium may be due to the degree of its toxicities to the inoculum, as nutrient level drops in the medium, and possibly the buildup of toxic metabolites that affected the microorganisms. This is an area of possible research by microbiologists. A greenish pigment was observed in the treated water released after stage two. This may be due to the metabolites produced by Pseudomonas aeruginosa [15].

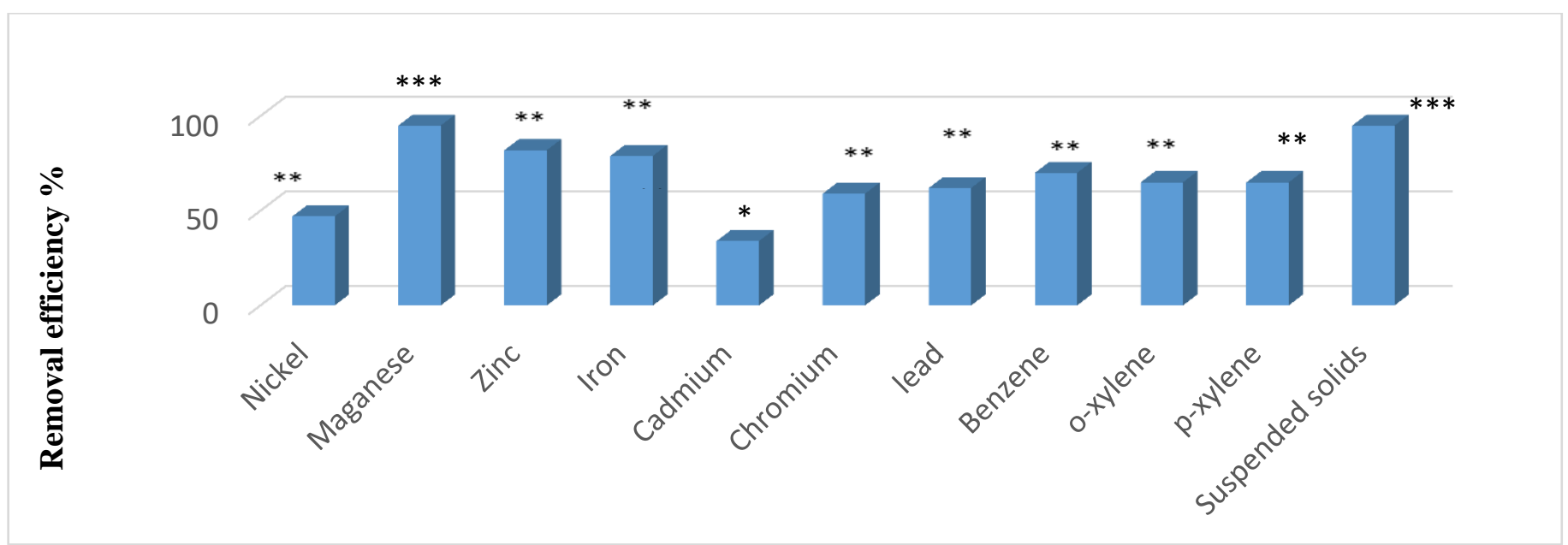

Fig. 10: Removal efficiency (RE) of the BPWTS.

LEGEND: *** Highest removal: suspended solids and manganese; ** Moderate removal: zinc, lead, benzene,o-xylene, p-xylene and chromium; * Pollutant with the lowest removal are nickel and cadmium

Pigmentation was observed in the treated water that came out from stage 2 when tap 3 was opened. Microorganisms naturally overcome high toxicity when faced with organic pollutants (hydrocarbons) removal, by the secretion of biosurfactants. The production of bio-surfactants, resulted into emulsification and solubilization of pollutants, consequently, their physical sequestration $[16,17,18,19]$. This facilitate the transport and translocation of the substrates, thus, increasing 
biosorption rate. The colouration, may be due to the production of rhamnolipids, a biosurfactants, commonly known to be produced by Pseudomonas aeruginosa[15]. This colouration of water has negative effect on its acceptability by water users. Further work is needed to find out causes of coloration. The processed African walnut seeds shells at stage 3, removed residual suspended solids in the treated water. The residual solids include dead and active microorganisms and bitumen solids. At stage 4, the granular activated carbon removed discolouration that was observed after stage 2 to permissible level, from 15.60 to $0.98 \mathrm{HU}$. As expected, activated charcoal is good discolouration sorbent [20,21]. The dosing of the treated water with chlorine, destroyed $P$. aeruginosa strains that might have passed through treatment stages (1 to 4) and prevented it from getting to the final treated water. Although, $P$. aeruginosa, is said to have no adverse effects on human being, disinfection was applied in case long duration of presence of the bacteria in humans may result in mutation into a strain that can adversely affect human beings[21].

The Removal Efficiency (Table 1) was calculated based on the test results of water pollution indicators before and after treatments as in Equation 1.

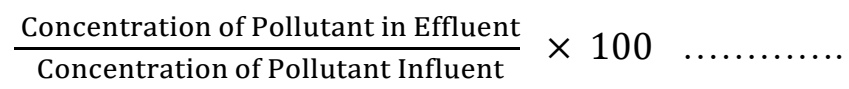

\section{Conclusion}

The bitumen-polluted water treatment systems (BPWTS) developed, substantially reduced the contaminants: suspended solids (1244 to $62 \mathrm{mg} / \mathrm{L})$, chromium $(2.72$ to $1.628 \mathrm{mg} / \mathrm{L})$ and benzene $(3.671$ to $2.5 \mu \mathrm{g} / \mathrm{L})$ found in the bitumen-polluted water. The maximum removal efficiency was $95.0 \%$ for suspended solids, and minimum for cadmium of $58 \%$.Other removals were for $70.0 \%$ hydrocarbon, $62.0 \%$ for lead $59.0 \%$ for chromium. $82.0 \%$ for zinc, $65.0 \%$ for oxylene $65.0 \%$, and $65.0 \%$ for p-xylene. Without decontamination, some of the water indicator levels especially lead and cadmium which were above several potable water criteria documented by National Environmental Standard and Regulation Enforcement Agency NESREA and World Health Organization WHO, would do serious harm to plants, animals and humans. The decontamination technique developed (the BPWTS), improved the water quality, and therefore has the potential of reducing the health risk to plants, animals and human beings lives in the bitumen affected areas.

\section{References}

[1] O. S. Adegoke, "Historical perspective of bitumen/tar sand development in Southwestern Nigeria," Proc. of the $1^{\text {st }}$ International Summit on Bitumen in Ondo State, Nigeria, pp.131-140, 2000.

[2] S. O. Adetola, "Investigation into physical and mechanical properties of few selected chicken feather commonly found in Nigeria," Ph.D. Thesis Ladoke Akintola University of Technology, Oyo State. Nigeria, 2015.

[3] B. Chen, L. Yan, X. Liu, and L. J. Worrall, "Poultry keratin based decolourant for dyeing wastewater treatment," Journal of Bioresources and Bio-products, vol.1, pp. 30-35, 2016.

[4] R. Wolfová, E. Pertile, and P. Fečko, "Removal of lead from aqueous solution by walnut shells," Journal of Environmental Chemistry and Ecotoxicology, vol. 5, no. 6, pp. 159-167, 2013.

[5] P. Kar, and M. Mitra, "Use of Keratin fibre for separation of heavy metals from water," Chem. Technol. Biotechnology, vol.79, pp. 113-1319, 2004.

[6] A. Ghosh, and H. Collie, "Keratinous materials as novel absorbent systems for toxic pollutants," Defence Science Journal, Heinemann, U.S.A, vol. 64, no. 3, pp. 209-221, 2014.

[7] K. O. Olayinka, "Pollutants in the environment: peregrination of an analytical chemist," University of Lagos, Nigeria Inaugural lecture series, University of Lagos, Nigeria, Press and Bookshop, 2016.

[8] S. C. U. Nwachukwu, P. James, and T. P. Gurney, "Inorganic nutrient utilization by adapted Pseudomonas putida strain used in the bioremediation of agricultural soil polluted with crude Petroleum," Journal of Environmental Biology, vol. 22, no. 3, pp. 153-162, 2001.

[9] R. M. Atlas, and A. Bartha, "Hydrocarbon biodegradation and an oil spill bioremediation," Adv. Microbial. Ecol., vol. 12, pp. 287-338, 1992.

[10] G. Umanu, S. C. U. Nwachukwu, and S. O. Oso, "Enhanced degradation of hydrocarbon in spent oil contaminated soil by Pseudomonas aeruginosa," International Journal of Science and Nature, U.S.A., vol .4, no. 4, pp. 611-618, 2013. 
[11] J. G. Leahy, and R. R. Colwell, "Pyrene Degradation of hydrocarbons in the environment, Microbiological fractions," Journal of Bacteriology, pp. 39-91, 1990.

[12] R. M. Atlas, "Microbial hydrocarbon degradation, bioremediation of oil spills," J. Chem. Tech. Biotech, vol. 52, pp. 149-157, 1991.

[13] R. Balance, and J. Bartram, Water quality monitoring - a practical guide to the design and implementation of fresh water quality and monitoring study UNEP/WHO. Chapman and Hall. London, UNEP/WHO, 1996.

[14] American Public Health Association (APHA), Standard Method for the Examination of Water and Waste water, 21st ed, Washington D.C, 2005.

[15] S. C. U. Nwachukwu, Personal Communication. University of Lagos, Nigeria 2014.

[16] G. M. Gadd, "Microbial influence on metal mobility and application for bioremediation," Geoderma, vol. 122, no. 2, pp. 610-617, 2004.

[17] G. L. Zhang, Y. Z. Wu, X. P. Qian, and Q. Meng, "Bioremediation of crude oil by Pseudomonas aeruginosa in the presence of rhamnolipds," Journal of Zheijang, University Science, vol. 6, no. 8, pp. 725-73, 2005.

[18] A. Soares dos Santos, N. Pereira Jr, and D. M. G. Freire, "Strategies for improved rhamnolipid production by Pseudomonas aeruginosa PAI," Peer J.DOI, pp. 1-16, 2016.

[19] O. O. Amund, and C. O. Igiri, "Biodegradation of petroleum hydrocarbon under tropical estuarine conditions," World Journal of Microbiology and Biotechnology, vol. 6, pp. 255-262, 2000.

[20] E. B. Lucas, "Activated charcoal as discolourant." Personal communication: Department of Agricultural \& Environmental Engineering, University of Ibadan, Ibadan, Nigeria. 2014.

[21] E. E. Atojunere, "Development of Filtration and Bioremediation technique to Decontaminate Bitumen-polluted water," Ph.D. Thesis, Department of Agricultural and Environmental Engineering, University of Ibadan, Ibadan, Nigeria 2017. 